\title{
Biomechanical loading during running: can a two mass-spring-damper model be used to evaluate ground reaction forces for high-intensity tasks?
}

Jasper Verheul ${ }^{\mathrm{a}}$, Niels J. Nedergaard ${ }^{\mathrm{a}, \mathrm{c}}$, Mark Pogson ${ }^{\mathrm{b}, \mathrm{d}}$, Paulo Lisboa ${ }^{\mathrm{b}}$, Warren Gregson ${ }^{\mathrm{a}}$, Jos Vanrenterghem ${ }^{\mathrm{a}, \mathrm{c}}$, Mark A. Robinson ${ }^{\mathrm{a}}$

${ }^{a}$ Research Institute for Sport and Exercise Sciences, Liverpool John Moores University, Liverpool, United Kingdom; ${ }^{b}$ Department of Applied Mathematics, Liverpool John Moores University, Liverpool, United Kingdom; ${ }^{c}$ Department of Rehabilitation Sciences, KU Leuven, Leuven, Belgium; ${ }^{d}$ Quintessa Ltd., Henley-on-Thames, United Kingdom

\section{Corresponding Address:}

Jasper Verheul, $\mathrm{PhD}$

Research Institute for Sport and Exercise Sciences

Liverpool John Moores University

Tom Reilly Building

Byrom Street

L3 5AF, Liverpool, United Kingdom

Email: J.P.Verheul@2016.ljmu.ac.uk 


\title{
1 Biomechanical loading during running: can a two mass-spring-damper \\ 2 model be used to evaluate ground reaction forces for high-intensity \\ 3 tasks?
}

4

\begin{abstract}
Running impact forces expose the body to biomechanical loads leading to beneficial adaptations, but also risk of injury. High-intensity running tasks especially, are deemed highly demanding for the musculoskeletal system, but loads experienced during these actions are not well understood. To eventually predict GRF and understand the biomechanical loads experienced during such activities in greater detail, this study aimed to 1) examine the feasibility of using a simple two mass-spring-damper model, based on eight model parameters, to reproduce ground reaction forces (GRFs) for high-intensity running tasks and 2) verify whether the required model parameters were physically meaningful. This model was used to reproduce GRFs for rapid accelerations and decelerations, constant speed running and maximal sprints. GRF profiles and impulses could be reproduced with low to very low errors across tasks, but subtler loading characteristics (impact peaks, loading rate) were modelled less accurately. Moreover, required model parameters varied strongly between trials and had minimal physical meaning. These results show that although a two mass-springdamper model can be used to reproduce overall GRFs for high-intensity running tasks, the application of this simple model for predicting GRFs in the field and/or understanding the biomechanical demands of training in greater detail is likely limited.
\end{abstract}

Keywords: GRF modelling, Model parameter optimisation, Training load monitoring, Whole-body loading, Biomechanical demands

Wordcount: 200 (abstract); 2598 (main text) 
In running-based sports, the different structures of the body are repetitively exposed to biomechanical loads. These loads can lead to beneficial adaptations on the one hand (Couppe et al., 2008; Timmins, Shield, Williams, Lorenzen, \& Opar, 2016), but also risk of injuries (Gabbett \& Ullah, 2012). High-intensity running tasks especially (e.g. accelerating, decelerating, sprinting) (Akenhead, French, Thompson, \& Hayes, 2014; Vigh-Larsen, Dalgas, \& Andersen, 2018), are deemed highly demanding for the musculoskeletal system, but the biomechanical loads experienced during these actions are not well understood (Vanrenterghem, Nedergaard, Robinson, \& Drust, 2017). Therefore, measuring and monitoring the ground reaction forces (GRFs) for these movements in non-laboratory settings would allow for a more detailed understanding of the biomechanical demands of training.

GRFs resulting from collisions with the ground during running are absorbed and returned by the body in a spring-like manner. Therefore, simple mass-spring models (single point mass attached to a spring) have been used to investigate various GRF characteristics (e.g. Blickhan, 1989; Dutto and Smith, 2002; Morin et al., 2005). The sinusoidal GRF profiles predicted by this model do however not accurately represent the typical double-peak GRF profiles of running (Alexander, Bennett, \& Ker, 1986; Bullimore \& Burn, 2007). These characteristic force peaks can substantially deviate between various tasks and are thus essential for examining the specific whole-body loads experienced during different running tasks. Based on the distinct contributions of the lower limb and upper body segments to the GRF during running (Bobbert, Schamhardt, \& Nigg, 1991; Clark, Ryan, \& Weyand, 2017), a two mass-spring-damper model can be used to describe the distinct impact and active peaks during simple elastic movements, i.e. steady running (Alexander et al., 1986; Derrick, Caldwell, \& Hamill, 2000). However, the ability of this model (which is based on eight parameters that 
52 describe simple mechanical characteristics of the body) to reproduce GRF profiles for

53 high-intensity running tasks is yet completely unknown.

54 If a simple two mass-spring-damper model can reproduce GRFs for non-elastic highintensity tasks, while retaining physically meaningful model parameters, this might eventually be used to predict GRF in the field and understand the biomechanical demands of such activities in greater detail. Therefore, this study aimed to use a two mass-spring-damper model to reproduce GRF profiles for activities that are frequently

59 performed during running-based sports. It was hypothesised that 1) this model could

60 accurately replicate measured GRF and loading characteristics for high-intensity

61 running tasks, and 2) that its model parameters could be used to evaluate the

62 biomechanical demands of these activities.

\section{Methods}

Fifteen healthy and physically active team-sports athletes participated in this study. Participants provided informed consent according to Liverpool John Moores University ethics regulations. After a warm-up, participants performed rapid accelerations from standstill to sprinting, decelerations from sprinting to standstill, and running trials at constant speeds from $2 \mathrm{~m} / \mathrm{s}$ to maximal sprinting speed ( 6-9 m/s, individual specific), with $1 \mathrm{~m} / \mathrm{s}$ stepwise increases. For each trial, GRF data were collected at $3000 \mathrm{~Hz}$ with a force platform (9287B, Kistler Holding AG, Winterthur,

71 Switzerland), filtered using a $50 \mathrm{~Hz}$ second-order Butterworth low-pass filter and normalised to body mass. To evaluate the total magnitude of load experienced during the different running tasks, resultant GRFs (overall whole-body loading) were calculated from the three force components and used for this investigation.

75 A two mass-spring-damper model described by eight natural model parameters (Figure 
1) was used to reproduce measured GRFs (Alexander et al., 1986; Derrick et al., 2000).

77 The model consisted of a lower mass $\mathrm{m}_{2}$ on a spring and damper, representing the support leg, with an upper mass $\mathrm{m}_{1}$ on a spring on top, representing the rest of the body. The positions of the upper and lower mass without any external load was described by $\mathrm{x}_{1}$ and $\mathrm{x}_{2}$, while $\mathrm{l}_{1}$ and $\mathrm{l}_{2}$ were the natural lengths of the upper and lower springs respectively. The linear spring stiffness constants for the upper and lower spring were defined as $\mathrm{k}_{1}$ and $\mathrm{k}_{2}$, while $\mathrm{c}$ was the damper's damping coefficient. From these nine parameters the eight natural parameters were derived according to Equations 1-8 (Table 1), with BM being the total body mass. The model's motion was described by the accelerations of its upper and lower mass (Table 1, Equation 9 and 10), in which $\mathrm{a}_{1,2}$, $\mathrm{v}_{1,2}$ and $\mathrm{p}_{1,2}$ were the upper and lower mass accelerations, velocities and positions respectively, $\lambda$ the upper mass ratio relative to the lower mass, $\omega_{1}$ and $\omega_{2}$ the natural frequencies of the upper and lower spring, $\zeta$ the damper's damping ratio, and $g$ the gravitational acceleration $\left(-9.81 \mathrm{~m} / \mathrm{s}^{2}\right)$. For each trial, a unique parameter set to fit modelled GRFs to measured GRFs was determined by solving Equations 9 and 10 (Table 1). The equations were solved with a purpose-written Python optimisation script, which included the L-BFGS-B numerical optimisation algorithm (Python, 2017; SciPy, 2017). Starting conditions for the optimisation were as described in Appendix A and parameters following from the optimisation process were used to calculate modelled GRFs (Table 1, Equation 11). Optimal model parameter combinations were determined by minimising the sum of the root mean square error (RMSE) of the GRF and its gradient, between modelled and measured GRF curves.

Modelled GRF accuracy was evaluated by RMSE and errors of relevant GRF loading characteristics impulse (area under the GRF curve), impact peak (force peak during the first $30 \%$ of stance) and loading rate (average GRF gradient from touch-down to impact 
101 peak). Error metrics were averaged across trials and participants for each task, i.e.

102 accelerations, decelerations, and running at constant low $(2-3 \mathrm{~m} / \mathrm{s})$, moderate $(4-5 \mathrm{~m} / \mathrm{s})$

103 and high $(>6 \mathrm{~m} / \mathrm{s})$ speeds. RMSE was rated very low (<1 N/kg), low $(1-2 \mathrm{~N} / \mathrm{kg})$,

104 moderate (2-3 N/kg), high (3-4 N/kg) or very high (>4 N/kg). GRF loading

105 characteristic errors were rated very low $(<5 \%)$, low $(5-10 \%)$, moderate $(10-15 \%)$, high

$106(15-20 \%)$ or very high (>20\%). Furthermore, correlation analyses were performed

107 between modelled and measured impulses, impact peaks and loading rates, and rated as

108 very weak $\left(\mathrm{R}^{2}<0.1\right)$, weak $\left(\mathrm{R}^{2}=0.1-0.3\right)$, moderate $\left(\mathrm{R}^{2}=0.3-0.5\right)$, strong $\left(\mathrm{R}^{2}=0.5-0.7\right)$,

109 very strong $\left(\mathrm{R}^{2}=0.7-0.9\right)$ or extremely strong $\left(\mathrm{R}^{2}=0.9-1\right)$ (Hopkins, Marshall,

110 Batterham, \& Hanin, 2009).

\section{Results}

112 GRF profiles were reproduced with high accuracy across tasks (Figure 2; Table

113 2). RMSE was very low for accelerations, as well as low- and moderate-speed running,

114 but increased for high-speed running and especially decelerations. Furthermore,

115 impulses were modelled with very high accuracy (errors $<1 \%$ ). Consequently, the

116 correlation between measured and modelled impulses was extremely strong $(\mathrm{p}<0.001)$

117 across tasks (Figure 3A) while errors were independent of task and magnitude (Figure

$1183 \mathrm{~B}$ and $\mathrm{C})$.

119 Since not all trials contained a distinct measured impact peak (e.g. accelerations (Figure

$1202 \mathrm{~A}$ ) or forefoot-strike sprints (Figure 2G)) and for several trials the impact peak could

121 not be modelled (Figure 2B, F and $\mathrm{H}$ ), only a select number of trials were included in

122 the impact peak and loading rate analysis (Table 2). Impact peaks were modelled with

123 low to moderate errors for constant speed running, but high to very high for

124 accelerations and decelerations. Similarly, modelled loading rate errors were high to 
125 very high across tasks. Nevertheless, modelled and measured impact peaks and loading

126 rates had an extremely strong correlation across tasks (Figure 3D and G). Absolute

127 errors significantly $(\mathrm{p}<0.001)$ increased for higher impact peaks and loading rates

128 (Figure 3E and $\mathrm{H}$ ), but relative errors remained constant independent of task and

129 magnitude (Figure 3F and I).

130 Despite the accurately reproduced GRF curves, all model parameters varied strongly

131 between and within tasks (Figure 4; Table 3). Especially motion ( $\left.\mathrm{p}_{1}, \mathrm{p}_{2}, \mathrm{v}_{1}, \mathrm{v}_{2}\right)$ and mass

$132(\lambda)$ related parameters were highly variable for decelerations, while $\omega_{1}$ and $\omega_{2}$ strongly

133 varied for all tasks. Although $\zeta$ varied less between tasks, within task variability was

134 large.

\section{Discussion and Implications}

136 The purpose of this study was to investigate whether a simple two mass-spring-

137 damper model can reproduce GRFs for high-intensity running tasks, while retaining

138 physically meaningful parameters. Across tasks, GRF curves could be reproduced with

139 low to moderate curve errors. The slightly higher errors observed in decelerations were

140 likely due to the distinct GRF profiles. The model typically underestimated the high

141 impact peaks and loading rates but overestimated the much lower second (active) peak

142 (Figure 2C and D). Previous studies also reported increased modelled curve errors in

143 tasks (Nedergaard, 2017) and individuals (Derrick et al., 2000) with considerably higher

144 impact peaks. Nedergaard (2017) suggested higher curve errors to be due to lower

145 spring stiffnesses, which reduces the magnitude of the impact peak (Derrick et al., 2000;

146 Nedergaard, 2017). Moreover, Derrick et al. (2000) showed that to increase the impact

147 peak, higher values are required for spring stiffnesses $\omega_{1}$ and $\omega_{2}$, upper mass velocity $v_{1}$

148 and mass ratio $\lambda$, together with a reduced damping ratio $\zeta$. In this study, mean $\mathrm{v}_{1}$ and $\lambda$ 
149 values were indeed substantially higher for decelerations compared to other tasks, but

$150 \omega_{1}, \omega_{2}$ and $\zeta$ were in a similar range as other tasks (Figure 4; Table 3). For GRF profiles

151 with high impact peaks, the model likely needs to adjust as many parameters as possible

152 to reproduce this first peak, while maintaining an accurate representation of the rest of

153 the curve characteristics (e.g. active peak, stance time).

154 Impulses were modelled with very high accuracy $(\approx 0.01 \mathrm{Ns} / \mathrm{kg})$ and had a perfect

155 correlation $\left(\mathrm{R}^{2}=1\right)$ with measured impulses. These results are in accordance with errors

$156 \quad(\approx 0.01 \mathrm{Ns} / \mathrm{kg})$ and correlations $\left(\mathrm{R}^{2}=0.98-1\right)$ found by Nedergaard $(2017)$, but much

157 lower than Derrick et al. (2000) who reported impulse errors of 5.5-8.5 Ns $(\approx 0.08-0.12$

$158 \mathrm{Ns} / \mathrm{kg}$ ). Since the latter study only optimised $\omega_{1}, \omega_{2}$ and $\mathrm{p}_{2}$, the better results in the

159 present study are likely the result of including all model parameters in the optimisation

160 process. Therefore, the two mass-spring-damper model can give very good estimates of

161 overall loading across tasks.

162 In contrast to overall loads, subtle loading characteristics (impact peak and loading rate)

163 were modelled less accurately. The initial force peak due to the lower limb colliding

164 with the ground (Clark et al., 2017), is typically followed by a slight decrease in GRF

165 before gradually increasing to the active peak caused by the upper body (Bobbert et al.,

166 1991). For accelerations and steady running this force decrease is small and forms a

167 minor part of the whole GRF profile. Since curve gradients and RMSEs were used as

168 model parameter optimisation criteria, a continuously rising curve from touch-down to

169 mid-stance (thus ignoring the impact peak) affected these criteria minimally. This

170 explains that for $99 \%$ of the decelerations, in which the impact peak dominates the GRF

171 profile, impact peaks were visible in the modelled curves, compared to only $34-48 \%$ for

172 accelerations and steady running. Moreover, impact peaks (and loading rates) were

173 typically underestimated with errors increasing for higher impact peaks. In general, 
174 differences between measured impact and active peaks increased for higher impact

175 peaks (compare for example Figures 2C and D). Most model parameters affecting the

176 impact peak influence the active peak simultaneously (Derrick et al., 2000). Therefore,

177 the model likely underestimated the higher impact peaks more, to limit the

178 overestimation of the second peak.

179 Despite the higher errors, correlations between measured and modelled impact peaks

180 and loading rates were extremely strong $\left(\mathrm{R}^{2}=0.96-0.97\right)$ (Figure $3 \mathrm{D}$ and $\left.\mathrm{G}\right)$. These

181 correlations are stronger than Udofa et al. (2016), who used a two mass model to

182 reproduce GRFs found correlations of $\mathrm{R}^{2}=0.82$ between measured and modelled impact

183 peaks, across different running speeds $(3-6 \mathrm{~m} / \mathrm{s})$ and loading conditions. The strong

184 linear relationships observed in this study (Figure 3A, D and G) might be used to adjust

185 modelled impact peaks and loading rates to get more accurate estimates of these loading

186 characteristics.

187 A limitation of the two mass-spring-damper model is the assumption of spring-like

188 (elastic) behaviour, meaning a constant spring stiffness during stance. Moreover, the

189 model's damper absorbs energy while energy producing elements are not included. The

190 leg is however known to be stiffer during landing than take-off (Blickhan, 1989), while

191 the muscle-tendon units produce more work during the push-off phase (Cavagna, 2006).

192 Although the high-intensity tasks investigated in this study seriously violated these

193 model assumptions, reproduced GRF profiles were fairly accurate. The model likely

194 overcompensates for the absence of active elements by substantially increasing its

195 stiffness (i.e. higher $\omega_{1}$ and $\omega_{2}$ ), in accordance with reduced energy requirements for

196 higher leg stiffness (Dutto \& Smith, 2002; McMahon \& Cheng, 1990). This might

197 explain why higher stiffness was observed for accelerations and high-speed running,

198 where the muscles need to produce more energy, compared to decelerations, where 
energy is primarily absorbed (Figure 4; Table 3). Due to the strong variability within

200 tasks however, parameters should be interpreted with caution.

201 Another limitation of this study is the complexity of model parameter combinations. As

202 described above, different parameters represent multiple physical aspects (e.g. leg

203 stiffness) and affect various GRF characteristics (e.g. impact peak, stance time) at the

204 same time (Derrick et al., 2000). During the optimisation process, numerical solvers

205 searched for optimal modelled GRF solutions in the highly complex eight-dimensional

206 parameter space. Therefore, numerous similarly good solutions might be found for

207 comparable GRF curves, leading to the high parameter variability and physically

208 unrealistic parameter values observed across trials (Table 3). For example, many

209 modelled GRF solutions were found to have $\lambda$ values larger than 20 , meaning that for

210 those trials the lower mass (support leg) was negligible relative to the rest of the body.

211 Model parameters found in this study therefore have little physical meaning, limiting

212 the biomechanical interpretability of the model. Moreover, an exploration during which

213 the parameter search spaces were restricted to physically meaningful values did not lead

214 to more consistency in parameter values within or between tasks, while the accuracy of

215 modelled GRF profiles was reduced (Appendix B).

216 A possible explanation for the limited model parameter interpretability described above,

217 is the choice to reproduce a three-dimensional (resultant) GRF with a one-dimensional

218 model. The authors chose to reproduce the total force magnitude to allow for

219 investigating the overall whole-body load experienced during the different running

220 tasks. Consequently, horizontal segmental movements leading to the horizontal forces

221 included in the resultant GRF, had to be accounted for by the vertical motion in the

222 model. Since vertical motion was described by the eight model parameters, this might

223 have contributed to the inconsistent parameter values observed and the lack of physical 
224 meaning. Horizontal movements and forces are, however, relatively small compared to

225 the vertical components, and are thus unlikely to have considerably affected the results

226 in this study. Moreover, exploratory work revealed that using the vertical component of

227 GRF only, did not noticeably improve the reproduced GRF profiles or enhance the

228 interpretability of the model parameters.

229 In this study, GRFs were reproduced by adjusting model parameters to fit measured

230 GRFs. However, in applied sport settings (e.g. football pitch, running track, etc.),

231 measured GRF is not available and other methods are required to estimate model

232 parameters and predict GRF. Since the two mass-spring-damper model's motion is

233 described by the acceleration of its masses, currently popular body-worn accelerometers

234 (Akenhead \& Nassis, 2016; Cardinale \& Varley, 2017) might be used to estimate the

235 parameters and predict GRFs in the field. However, the large variability and minimal

236 physical meaning of the model parameter values likely limit the usefulness of this

237 approach.

\section{Conclusion}

239 This study aimed to use a two mass-spring-damper model to reproduce GRF

240 profiles for activities that are frequently performed during running-based sports. As

241 hypothesised, the model could be used to reproduce overall GRF profiles for high-

242 intensity running tasks. However, the required model parameters varied strongly

243 between trials and had minimal physical meaning, rejecting our second hypothesis.

244 Therefore, the application of this specific two mass-spring-damper model for predicting

245 GRFs in the field and/or understanding the mechanical aspects of the running tasks

246 investigated in greater detail is likely limited. 


\section{References}

248 Akenhead, R., French, D., Thompson, K. G., \& Hayes, P. R. (2014). The acceleration dependent validity and reliability of $10 \mathrm{~Hz}$ GPS. Journal of Science and Medicine in Sport, 17(5), 562-566. doi: 10.1016/j.jsams.2013.08.005

Akenhead, R., \& Nassis, G. P. (2016). Training load and player monitoring in highlevel football: Current practice and perceptions. International Journal of Sports Physiology and Performance, 11(5), 587-593. doi: 10.1123/ijspp.2015-0331

Alexander, R. M., Bennett, M. B., \& Ker, R. F. (1986). Mechanical properties and function of the paw pads of some mammals. Journal of Zoology, 209, 405-419.

Blickhan, R. (1989). The spring-mass model for running and hopping. Journal of Biomechanics, 22(11), 1217-1227.

Bobbert, M. F., Schamhardt, H. C., \& Nigg, B. M. (1991). Calculation of vertical ground reaction force estimates during running from positional data. Journal of Biomechanics, 24(12), 1095-1105. doi: 10.1016/0021-9290(91)90002-5

Bullimore, S. R., \& Burn, J. F. (2007). Ability of the planar spring-mass model to predict mechanical parameters in running humans. Journal of Theoretical Biology, 248(4), 686-695. doi: 10.1016/j.jtbi.2007.06.004

Cardinale, M., \& Varley, M. C. (2017). Wearable training-monitoring technology: applications, challenges, and opportunities. International Journal of Sports Physiology and Performance, 12(S2), 55-62.

Cavagna, G. A. (2006). The landing-take-off asymmetry in human running. The Journal of Experimental Biology, 209, 4051-60. doi: 10.1242/jeb.02344

Clark, K. P., Ryan, L. J., \& Weyand, P. G. (2017). A general relationship links gait mechanics and running ground reaction forces. The Journal of Experimental

272 Couppe, C., Kongsgaard, M., Aagaard, P., Hansen, P., Bojsen-Moller, J., Kjaer, M., \& Magnusson, S. P. (2008). Habitual loading results in tendon hypertrophy and increased stiffness of the human patellar tendon. Journal of Applied Physiology, 105(3), 805-810. doi: 10.1152/japplphysiol.90361.2008

Dempster, W. T. (1955). Space requirements of the seated operator: geometrical, 
kinematic, and mechanical aspects of the body with special reference to the limbs. WADC Technical Report, 55-159.

Derrick, T. R., Caldwell, G. E., \& Hamill, J. (2000). Modeling the stiffness characteristics of the human body while running with various stride lengths. Journal of Applied Biomechanics, 16, 36-51.

Dutto, D. J., \& Smith, G. a. (2002). Changes in spring-mass characteristics during treadmill running to exhaustion. Medicine \& Science in Sports \& Exercise, 34(8), 1324-1331.

Gabbett, T. J., \& Ullah, S. (2012). Relationship between running loads and soft-tissue injury in elite team sport athletes. Journal of Strength and Conditioning Research, 26(4), 953-960.

Hopkins, W. G., Marshall, S. W., Batterham, A. M., \& Hanin, J. (2009). Progressive statistics for studies in sports medicine and exercise science. Medicine and Science in Sports and Exercise, 41(1), 3-12. doi: 10.1249/MSS.0b013e31818cb278

McMahon, T. A., \& Cheng, G. C. (1990). The mechanics of running: how does stiffness couple with speed? Journal of Biomechanics, 23(SUPPL. 1), 65-78. doi: 10.1016/0021-9290(90)90042-2

Morin, J.-B., Dalleau, G., Kyröläinen, H., Jeannin, T., \& Belli, A. (2005). A simple method for measuring stiffness during running. Journal of Applied Biomechanics, 21(2), 167-180. doi: 10.1519/JSC.0b013e318260edad

Nedergaard, N. J. (2017). Whole-body biomechanical load monitoring from accelerometry in team sports. PhD Thesis. Liverpool John Moores University, Liverpool. Retrieved from http://researchonline.ljmu.ac.uk/5469/

Python. (2017). Python Software Foundation, 2017, Python Language Reference, version 2.7. Available at http://www.python.org.

SciPy. (2017). SciPy 0.19.1, Available at https://scipy.org.

Timmins, R. G., Shield, A. J., Williams, M. D., Lorenzen, C., \& Opar, D. A. (2016). Architectural adaptations of muscle to training and injury: a narrative review outlinig the contributions by fascicle length, pennation angle and muscle thickness. British Journal of Sports Medicine, 50, 1467-1472. doi: 10.1136/bjsports-2015094881 
308 Udofa, A. B., Ryan, L. J., \& Weyand, P. G. (2016). Impact Forces During Running:

309 Loaded Questions, Sensible Outcomes. In IEEE 13th International Conference on

$310 \quad$ Wearable and Implantable Body Sensor Networks (BSN) (pp. 371-376).

311 Vanrenterghem, J., Nedergaard, N. J., Robinson, M. A., \& Drust, B. (2017). Training

312 load monitoring in team sports: a novel framework separating physiological and

313 biomechanical load-adaptation pathways. Sports Medicine. doi: 10.1007/s40279-

$314 \quad 017-0714-2$

315 Vigh-Larsen, J. F., Dalgas, U., \& Andersen, T. B. (2018). Position-specific acceleration

316 and deceleration profiles in elite youth and senior soccer players. Journal of

317 Strength and Conditioning Research, 32(4), 1114-1122. doi:

$318 \quad 10.1519 / \mathrm{JSC} .0000000000001918$

319

320 


\section{Appendix A}

The model parameter optimisation process for accurately reproducing ground

323 reaction forces (GRFs) described in this study, requires the definition of starting

324 conditions for the different parameters. Therefore, a pilot analysis was performed with

325 the model parameters as defined by Derrick et al. (2000), who used the two mass-

326 spring-damper model for constant speed running at $3.83 \mathrm{~m} / \mathrm{s}( \pm 5 \%)$ (Table A1). To

327 verify if these parameters were appropriate as starting conditions for reproducing the

328 GRF profiles for the high-intensity tasks investigated in this study, GRF data for these

329 tasks were modelled for four randomly selected participants. The parameter values

330 reported by Derrick et al. (2000) were used as initial starting conditions for the

331 parameters. After this optimisation process, the resulting median model parameters

332 (Table A1) from this analysis were then used as starting conditions for the whole data

333 set. 


\section{Appendix B}

The two mass-spring-damper model parameters found in this study varied

strongly within and between tasks and had little physical meaning, limiting the model's

338 interpretability. However, due to the highly complex eight-dimensional parameter space, several parameter combinations might result in similarly accurate modelled ground reaction force (GRF) solutions. If the model can accurately replicate GRF

341 profiles across tasks within a range of values that are more physically meaningful, this

342 may improve the interpretability of the model parameters. Therefore, GRF profiles were

343 reproduced with the two mass-spring-damper model within a predefined range of model

344 parameter values. The model's mass ratio $\lambda$ was fixed at a value of 3 au (i.e. lower mass

$345 \sim 25 \%$ of the total body mass), which was estimated from previously described

346 segmental properties of the foot, shank, thigh and pelvis (Dempster, 1955). In addition,

347 the remaining parameter search windows were limited to a range of values that was

348 deemed theoretically reasonable and physically meaningful (note: $\mathrm{p}_{2}$ was calculated

349 from $\left.v_{2}\right)$.

350

$$
\text { - } \mathrm{p}_{1}=-0.4-0.1 \mathrm{~m}
$$$$
\text { - } \mathrm{v}_{1}=-3-1 \mathrm{~m} / \mathrm{s}
$$$$
\text { - } \mathrm{v}_{2}=-0.5-2 \mathrm{~m} / \mathrm{s}
$$$$
\text { - } \omega_{1}=0-50 \mathrm{~N} / \mathrm{m} / \mathrm{kg}
$$$$
\text { - } \omega_{2}=0-174 \mathrm{~N} / \mathrm{m} / \mathrm{kg}
$$$$
-\lambda=3 \mathrm{au}
$$

Root mean square errors (RMSE) of the reproduced GRF profiles from a limited range of parameter values increased for accelerations $(+106 \%)$, decelerations $(+6 \%)$ and running at constant low $(+29 \%)$, moderate $(+10 \%)$ and high $(+20 \%)$ speeds, compared 
360 to using free parameters search windows. Moreover, the model parameters required to

361 reproduce the measured GRF profiles strongly varied within the defined parameter

362 boundaries (Figure B1). There was no consistency of parameters values within or

363 between any of the parameters or tasks. Moreover, many trials required parameter

364 values equal to the set upper or lower limit of different parameters, indicating the need

365 for higher or lower values than physically reasonable. Therefore, it was concluded that

366 the two mass-spring-damper model cannot be used to replicate GRF profiles with high

367 accuracy across a range of running tasks, using physically meaningful model

368 parameters. 
Table 1 Equations describing the eight natural parameters of the two mass-springdamper model

\begin{tabular}{|c|c|c|}
\hline Initial position of the upper mass & $\mathrm{p}_{1}=\mathrm{x}_{1}-\mathrm{l}_{1}-\mathrm{l}_{2}$ & Equation 1 \\
\hline Initial position of the lower mass & $\mathrm{p}_{2}=\mathrm{x}_{2}-\mathrm{l}_{2}$ & Equation 2 \\
\hline Initial velocity of the upper mass & $\mathrm{v}_{1}=\dot{\mathrm{p}_{1}}$ & Equation 3 \\
\hline Initial velocity of the lower mass & $\mathrm{v}_{2}=\mathrm{p}_{2}$ & Equation 4 \\
\hline Mass ratio & $\lambda=\frac{\mathrm{m}_{1}}{\mathrm{~m}_{2}}$ & Equation 5 \\
\hline $\begin{array}{l}\text { Natural frequency of the upper } \\
\text { spring }\end{array}$ & $\omega_{1}=\sqrt{\frac{\mathrm{k}_{1}}{\mathrm{~m}_{1}}}=\sqrt{\frac{(1+\lambda) \cdot \mathrm{k}_{1}}{\lambda \cdot \mathrm{BM}}}$ & Equation 6 \\
\hline $\begin{array}{l}\text { Natural frequency of the lower } \\
\text { spring }\end{array}$ & $\omega_{2}=\sqrt{\frac{\mathrm{k}_{2}}{\mathrm{~m}_{2}}}=\sqrt{\frac{(1+\lambda) \cdot \mathrm{k}_{2}}{\mathrm{BM}}}$ & Equation 7 \\
\hline Damping ratio of the damper & $\zeta=\frac{\mathrm{c}}{2 \cdot \sqrt{\mathrm{k}_{2} \cdot \mathrm{m}_{2}}}$ & Equation 8 \\
\hline Acceleration of the upper mass & $a_{1}=-\omega_{1}^{2} \cdot\left(p_{1}-p_{2}\right)+g$ & Equation 9 \\
\hline Acceleration of the lower mass & $\begin{array}{c}a_{2}=-\omega_{2}^{2} \cdot p_{2}+\omega_{1}^{2} \cdot \lambda \cdot\left(p_{1}-p_{2}\right)- \\
2 \cdot \zeta \cdot \omega_{2} \cdot v_{2}+g\end{array}$ & Equation 10 \\
\hline Ground reaction force & $\mathrm{GRF}=-\frac{\mathrm{BM} \cdot \omega_{2}}{1+\lambda} \cdot\left(\omega_{2} \cdot \mathrm{p}_{2}+2 \cdot \zeta \cdot \mathrm{v}_{2}\right)$ & Equation 11 \\
\hline
\end{tabular}


Table 2 Modelled ground reaction force curve and loading characteristics errors

\begin{tabular}{|c|c|c|c|c|c|c|c|c|}
\hline & \multicolumn{2}{|c|}{ RMSE } & \multicolumn{2}{|c|}{ Impulse error } & \multicolumn{2}{|c|}{$\begin{array}{c}\text { Impact peak } \\
\text { error }\end{array}$} & \multicolumn{2}{|c|}{ Loading rate error } \\
\hline & $\mathrm{N} / \mathrm{kg}$ & $\%$ & $\mathrm{Ns} / \mathrm{kg}$ & $\%$ & $\mathrm{~N} / \mathrm{kg}$ & $\%$ & $\mathrm{~N} / \mathrm{kg} / \mathrm{s}$ & $\%$ \\
\hline Accelerations $(n=189)$ & $\begin{array}{c}0.69 \\
\pm 0.47\end{array}$ & $\begin{array}{c}9.9 \\
\pm 6.4\end{array}$ & $\begin{array}{c}0.01 \\
\pm 0.01\end{array}$ & $\begin{array}{c}0.6 \\
\pm 0.5\end{array}$ & $\begin{array}{c}2.43 \\
\pm 1.49\end{array}$ & $\begin{array}{r}18.9 \\
\pm 11.7\end{array}$ & $\begin{array}{c}487 \\
\pm 342\end{array}$ & $\begin{array}{c}31.3 \\
\pm 19.9\end{array}$ \\
\hline Decelerations $(n=240)$ & $\begin{array}{c}2.48 \\
\pm 1.17\end{array}$ & $\begin{array}{c}33.9 \\
\pm 28.3\end{array}$ & $\begin{array}{c}0.01 \\
\pm 0.01\end{array}$ & $\begin{array}{c}0.7 \\
\pm 0.5\end{array}$ & $\begin{array}{c}7.43 \\
\pm 4\end{array}$ & $\begin{array}{c}20.6 \\
\pm 13.7\end{array}$ & $\begin{array}{c}431 \\
\pm 276\end{array}$ & $\begin{array}{r}18.7 \\
\pm 9.4\end{array}$ \\
\hline Constant speed running & & & & & & & & \\
\hline Low $(2-3 \mathrm{~m} / \mathrm{s} ; \mathrm{n}=126)$ & $\begin{array}{c}0.48 \\
\pm 0.22\end{array}$ & $\begin{array}{c}7.6 \\
+5.8\end{array}$ & $\begin{array}{c}0.01 \\
\pm 0\end{array}$ & $\begin{array}{c}0.4 \\
\pm 0.3\end{array}$ & $\begin{array}{c}1.53 \\
\pm 1.25\end{array}$ & $\begin{array}{l}10.2 \\
\pm 8.5\end{array}$ & $\begin{array}{c}200 \\
\pm 116\end{array}$ & $\begin{array}{r}19.1 \\
\pm 9.8\end{array}$ \\
\hline Moderate $(4-5 \mathrm{~m} / \mathrm{s} ; \mathrm{n}=126)$ & $\begin{array}{c}0.78 \\
\pm 0.25\end{array}$ & $\begin{array}{c}9.4 \\
\pm 3.9\end{array}$ & $\begin{array}{c}0.01 \\
\pm 0\end{array}$ & $\begin{array}{c}0.3 \\
\pm 0.2\end{array}$ & $\begin{array}{c}1.54 \\
\pm 0.86\end{array}$ & $\begin{array}{c}7.5 \\
\pm 4.2\end{array}$ & $\begin{array}{c}254 \\
\pm 101\end{array}$ & $\begin{array}{l}20.8 \\
\pm 6.9\end{array}$ \\
\hline $\operatorname{High}(>6 \mathrm{~m} / \mathrm{s} ; \mathrm{n}=176)$ & $\begin{array}{c}1.21 \\
\pm 0.56\end{array}$ & $\begin{array}{l}13.6 \\
\pm 7.1\end{array}$ & $\begin{array}{c}0.01 \\
\pm 0\end{array}$ & $\begin{array}{c}0.3 \\
\pm 0.2\end{array}$ & $\begin{array}{c}2.99 \\
\pm 1.74\end{array}$ & $\begin{array}{c}12 \\
\pm 8.1\end{array}$ & $\begin{array}{c}287 \\
\pm 156\end{array}$ & $\begin{array}{l}18.4 \\
\pm 9.7\end{array}$ \\
\hline All tasks $(\mathrm{n}=857)$ & $\begin{array}{c}1.28 \\
\pm 1.06\end{array}$ & $\begin{array}{c}17 \\
\pm 19.1\end{array}$ & $\begin{array}{c}0.01 \\
\pm 0.01\end{array}$ & $\begin{array}{c}0.5 \\
\pm 0.4\end{array}$ & $\begin{array}{c}5.74 \\
\pm 3.85\end{array}$ & $\begin{array}{c}17.4 \\
\pm 12.2\end{array}$ & $\begin{array}{c}385 \\
\pm 247\end{array}$ & $\begin{array}{c}20.3 \\
\pm 10.7\end{array}$ \\
\hline
\end{tabular}

Mean \pm standard deviations for root mean square errors (RMSE), impulse, impact peak and loading rate errors of the modelled GRF profiles for different tasks. Values are either absolute or relative errors compared to the measured GRF. Impact peak and loading rate (grey shaded) was modelled for 34\%, 99\% and $48 \%$ of the acceleration, deceleration and constant speed running trials respectively.

Table 3 Mean \pm standard deviation values for the eight model parameters for the different tasks

\begin{tabular}{|c|c|c|c|c|c|c|c|c|}
\hline & $\begin{array}{c}\mathbf{p}_{1} \\
(\mathbf{m})\end{array}$ & $\begin{array}{c}\mathbf{p}_{2} \\
(\mathbf{m})\end{array}$ & $\begin{array}{c}\mathbf{V} 1 \\
(\mathbf{m} / \mathbf{s}) \\
\end{array}$ & $\begin{array}{c}\mathbf{v}_{2} \\
(\mathbf{m} / \mathbf{s}) \\
\end{array}$ & $\begin{array}{c}\omega_{1} \\
(\mathrm{~N} / \mathbf{m} / \mathbf{k g})\end{array}$ & $\begin{array}{c}\omega_{2} \\
(\mathrm{~N} / \mathbf{m} / \mathbf{k g})\end{array}$ & $\begin{array}{c}\lambda \\
\text { (au) }\end{array}$ & $\begin{array}{c}\zeta \\
(\mathrm{au})\end{array}$ \\
\hline Accelerations & $\begin{array}{c}0.09 \\
\pm 8.19\end{array}$ & $\begin{array}{c}-0.7 \\
\pm 5.47\end{array}$ & $\begin{array}{c}16.5 \\
\pm 146.03\end{array}$ & $\begin{array}{c}0.37 \\
\pm 5.03\end{array}$ & $\begin{array}{c}32 \\
\pm 27\end{array}$ & $\begin{array}{c}102 \\
\pm 155\end{array}$ & $\begin{array}{c}0.4 \\
\pm 2.29\end{array}$ & $\begin{array}{r}0.9 \\
\pm 3.9\end{array}$ \\
\hline Decelerations & $\begin{array}{l}-12.97 \\
\pm 26.35\end{array}$ & $\begin{array}{l}-0.33 \\
\pm 1.18\end{array}$ & $\begin{array}{c}80.98 \\
\pm 184.71\end{array}$ & $\begin{array}{c}45.87 \\
\pm 132.34\end{array}$ & $\begin{array}{c}24 \\
\pm 32\end{array}$ & $\begin{array}{l}114 \\
\pm 91\end{array}$ & $\begin{array}{c}161.4 \\
\pm 474.73\end{array}$ & $\begin{array}{c}0.4 \\
\pm 0.5\end{array}$ \\
\hline \multicolumn{9}{|l|}{ Constant speed running } \\
\hline Low $(2-3 \mathrm{~m} / \mathrm{s})$ & $\begin{array}{c}0.63 \\
\pm 3.14\end{array}$ & $\begin{array}{c}0.07 \\
\pm 1.22\end{array}$ & $\begin{array}{c}-2.89 \\
\pm 56.17\end{array}$ & $\begin{array}{l}-0.12 \\
\pm 1.22\end{array}$ & $\begin{array}{c}31 \\
\pm 28\end{array}$ & $\begin{array}{c}72 \\
\pm 78\end{array}$ & $\begin{array}{l}5.87 \\
\pm 5.9\end{array}$ & $\begin{array}{c}0.9 \\
\pm 2.4\end{array}$ \\
\hline Moderate $(4-5 \mathrm{~m} / \mathrm{s})$ & $\begin{array}{l}0.91 \\
\pm 5.2\end{array}$ & $\begin{array}{l}0.09 \\
\pm 0.8\end{array}$ & $\begin{array}{l}12.67 \\
\pm 137\end{array}$ & $\begin{array}{c}-0.2 \\
\pm 1.13\end{array}$ & $\begin{array}{c}37 \\
\pm 35\end{array}$ & $\begin{array}{c}101 \\
\pm 106\end{array}$ & $\begin{array}{c}4.16 \\
\pm 6.34\end{array}$ & $\begin{array}{c}0.6 \\
\pm 1.1\end{array}$ \\
\hline $\operatorname{High}(>6$ m/s) & $\begin{array}{c}-2.21 \\
\pm 13.37\end{array}$ & $\begin{array}{c}-1.74 \\
\pm 10.31\end{array}$ & $\begin{array}{l}-1.83 \\
\pm 115\end{array}$ & $\begin{array}{c}0.98 \\
\pm 12.62\end{array}$ & $\begin{array}{c}34 \\
\pm 35\end{array}$ & $\begin{array}{c}134 \\
\pm 148\end{array}$ & $\begin{array}{c}1.93 \\
\pm 4.99\end{array}$ & $\begin{array}{l}1.9 \\
\pm 7\end{array}$ \\
\hline All tasks & $\begin{array}{c}-4 \\
\pm 17.12\end{array}$ & $\begin{array}{l}-0.57 \\
\pm 5.32\end{array}$ & $\begin{array}{c}28.49 \\
\pm 146.94\end{array}$ & $\begin{array}{c}13.71 \\
\pm 74.86\end{array}$ & $\begin{array}{c}31 \\
\pm 32\end{array}$ & $\begin{array}{c}109 \\
\pm 129\end{array}$ & $\begin{array}{c}49.38 \\
\pm 267.09\end{array}$ & $\begin{array}{c}0.9 \\
\pm 3.7\end{array}$ \\
\hline
\end{tabular}


Table A1 Initial conditions for the model's eight parameter values for reproducing GRF

\begin{tabular}{|c|c|c|c|c|c|c|c|c|}
\hline & $\begin{array}{c}\mathbf{p}_{1} \\
(\mathbf{m})\end{array}$ & $\begin{array}{c}\mathbf{p}_{2} \\
(\mathbf{m})\end{array}$ & $\begin{array}{c}\mathbf{v}_{1} \\
(\mathbf{m} / \mathbf{s})\end{array}$ & $\begin{array}{c}\mathbf{v}_{2} \\
(\mathbf{m} / \mathbf{s})\end{array}$ & $\begin{array}{c}\omega_{1} \\
(\mathrm{~N} / \mathrm{m} / \mathbf{k g}) \\
\end{array}$ & $\begin{array}{c}\omega_{2} \\
(\mathrm{~N} / \mathrm{m} / \mathbf{k g})\end{array}$ & $\begin{array}{c}\lambda \\
\text { (au) }\end{array}$ & $\begin{array}{c}\zeta \\
(\mathrm{au})\end{array}$ \\
\hline $\begin{array}{l}\text { Derrick et al. } \\
\text { (2000) }\end{array}$ & $0.015^{*}$ & 0.0074 & -0.73 & -0.66 & $207 * *$ & $626 * *$ & 2 & 0.35 \\
\hline Optimised & -0.01 & 0.00 & -1.29 & -0.19 & 18.33 & 58.32 & 2.81 & 0.31 \\
\hline \multicolumn{9}{|c|}{$\begin{array}{l}\text { The starting parameter values for the model optimisation process as described by Derrick } \\
\text { et al. (2000) and those following from a pilot analysis using data for high-intensity running } \\
\text { tasks. New (optimised) starting parameters are median values. } \\
* \text { The upper mass position } p_{1} \text { was not reported and its value was estimated to be double } \\
\text { that of the position } p_{2} \text { of the lower mass. } \\
\text { ** The natural spring frequency values were estimated from the reported spring stiffness } \\
\text { values } k_{1} \text { and } k_{2} \text {. }\end{array}$} \\
\hline
\end{tabular}


376 Figure 1 The two mass-spring-damper model consisted of a lower mass $\left(\mathrm{m}_{2}\right)$

377 representing the support leg and an upper mass $\left(\mathrm{m}_{1}\right)$ representing the rest of the body.

378 Both masses were given an initial position $\left(\mathrm{p}_{1}, \mathrm{p}_{2}\right)$ and velocity $\left(\mathrm{v}_{1}, \mathrm{v}_{2}\right)$, and the mass

379 ratio $\lambda$ was defined as the upper mass relative to the lower mass $\left(\mathrm{m}_{1} / \mathrm{m}_{2}\right)$. The stiffnesses

380 of the upper and lower spring were defined by their natural frequencies $\left(\omega_{1}, \omega_{2}\right)$ and the

381 model was damped by a damping coefficient $\zeta$. The model's motion was described by

382 the acceleration of its two masses $\left(\mathrm{a}_{1}, \mathrm{a}_{2}\right)$ based on the eight natural model parameters,

383 from which the modelled GRF was calculated. 
384 Figure 2 Typical examples of measured (black continuous line) and modelled (red 385 dotted line) ground reaction force (GRF) profiles including the root mean squared error 386 (RMSE) between both curves. 
387 Figure 3 Errors for relevant ground reaction force (GRF) loading characteristics

388 impulse, impact peak and loading rate for accelerations (blue circles), decelerations (red 389 triangles), and running at a constant low (light grey crosses), moderate (dark grey

390 crosses) and high (black crosses) speed. Negative errors are an underestimation of the 391 measured value and positive errors and overestimation. 
392 Figure 4 Model parameter values for accelerated, decelerated, and low-, moderate- and

393 high-speed running. Means (black dotted line) and standard deviations (grey dashed 394 line) were taken across tasks. 
395 Figure B1 Model parameter values for accelerated, decelerated, and low-, moderate-

396 and high-speed running. Mass ratio $\lambda$ was fixed at $3 \mathrm{au}$, while the other parameters were 397 bound to a range of values deemed physically reasonable. 